\title{
Optimization on Proportion for Recycled Aggregate in Concrete Using Two-Stage Mixing Approach
}

\author{
Vivian W. Y. Tam ${ }^{1}$, C. M. Tam ${ }^{2}$ and Y. Wang ${ }^{3}$
}

\begin{abstract}
Recycled aggregate (RA) is well acknowledged having a poorer quality due to its higher porosity resulted from cement mortar remains attaching to its surface that hampers the recycling rate of concrete waste. Many previous researches recorded reduction in strength for concrete made with RA. As a result, the use of RA is mainly confined to low-grade applications. Tam et al. [6] proposed a two-stage mixing approach (TSMA) for improving the strength of recycled aggregate concrete (RAC), by testing mixes with up to 30 percent RA replacement. This paper extends Tam et al.'s work [6] by exploring RA substitutions ranging from 0 and 100 percent and compares their performance with the traditional mixing procedure. Based upon the experimental works, improvements on strength and rigidity of RAC using TSMA were compared with those of traditional mixing procedure based on different percentages of RA replacements. The results were then optimized using General Regression Neural Networks (GRNN) and RA replacements of 25 to 40 percent and 50 to 70 percent were found to be optimal when TSMA was adopted. It confirms the conservative recommendation of $20 \%$ RA substitution by many previous researchers and public users.
\end{abstract}

Keywords: optimization, strength, recycled aggregate, concrete, construction

\footnotetext{
${ }^{1 *}$ Corresponding Author, Lecturer, Griffith School of Engineering, Gold Coast Campus, Griffith University PMB50 Gold Coast Mail Centre, Queensland 9726, Australia. Email: v.tam@griffith.edu.au

2 Professor, Department of Building \& Construction, City University of Hong Kong, 83 Tat Chee Avenue, Kowloon, Hong Kong.

${ }^{3}$ Research Student, Department of Computer Science, Tsinghua University
} 


\section{Introduction}

Sustainable development has been advocated all over the world [1]. ERL [2] indicated that the amount of demolition debris dumped at landfill sites in the United Kingdom is in excess of 20 million tons per annum. The bulk of this material is concrete (50 to 55\%) and masonry (30 to $40 \%$ ) with only small percentages of other materials such as metals, glass and timber [3]. Recovery of these waste materials can reduce the consumption rate of landfill areas and natural gravel resources.

In the Netherlands, about 14 million tons of building and demolishing wastes per annum are produced, in which about 8 million tons are recycled, mainly for unbound road base courses [4]. National waste strategies in UK require increase in household waste recycling and recovery rates and these measures will require the development of the infrastructure to support national highintensity recycling and composting schemes and the construction of at least 35 new municipal wastes incinerators. Although $40 \%$ of demolition waste in the United Kingdom is recycled, they are mainly used for low grade application such as fills and hardcore. Higher grade utilization such as concrete has been discouraged by a lack of suitable specifications [5]. The demand from low grade applications is almost saturated and a further increase in reuse must be realized through other sectors of the building industry, such as aggregates for concrete.

This paper aims at the following objectives:

i) Study the extent of construction waste;

ii) Examination of the current obstacles on recycling concrete wastes;

iii) Comparison and analysis of recycled aggregate concrete (RAC) made from the two-stage 
mixing approach (TSMA) developed by Tam et al. [6] with recycled aggregate (RA) replacements ranging from 0 to 100 percent and that of the traditional mixing procedure; and

iv) Optimization of percentages of RA replacements using TSMA by General Regression Neural Networks (GRNN).

\section{Obstacles in Using Recycled Aggregate}

Although it is environmentally beneficial to use RA, the current legislation and experience, however, are not sufficient to support and encourage recycling of demolished concrete waste. These technical problems, include weak interfacial transition zones between cement paste and aggregate, porosity and traverse cracks within demolished concrete, high level of sulphate and chloride contents, impurity, cement remains, poor grading, high variations in quality, which render the use of RA for structural applications difficult [7-8].

\section{Two-Stage Mixing Approach}

In order to improve the quality of recycled aggregate concrete, a mixing method: Two-Stage Mixing Approach (TSMA) was developed by Tam et al. [6], which divides the mixing process into two parts and proportionally splits the required water into two parts which are added after mixing one part with fine and coarse aggregate and cement; while the normal mixing approach only puts all the ingredients of concrete and mix them. Improvement of strength can be achieved up to 21.19 percent for 20 percent of RA under 28-day curing conditions using TSMA as recorded by Tam et al. [6]. 


\section{Experimental Method}

The experimental works by Tam et al. [6] was limited to 30 percent RA substitutions. This study further explores RA replacement ratios of $40 \%, 50 \%, 60 \%, 70 \%, 80 \%, 90 \%$ and $100 \%$ experimented under the normal mixing approach (NMA) and TSMA in addition to the proportions of $0 \%, 5 \%, 10 \%, 15 \%, 20 \%, 25 \%$ and $30 \%$ previously recorded by Tam et al. [6]. The designated mix proportions follow the specifications of Buildings Department (BD) of the Hong Kong Special Administrative Region [9] with 1:1.8:1.8:0.9 (ordinary Portland cement / fine aggregate / 20mm coarse aggregate / 10mm coarse aggregate) with a water/cement ratio of 0.45 and grading requirements according to BS 882 [10].

The RA used for the experiments were collected from the Tuen Mun Area 38 recycling plant with average absorption values of $1.65 \%$ for $20 \mathrm{~mm}$ and $2.63 \%$ for $10 \mathrm{~mm}$ aggregate. The quality of RA is poorer than virgin aggregate (water absorption of virgin aggregate at $0.77 \%$ and $0.57 \%$ for $20 \mathrm{~mm}$ and $10 \mathrm{~mm}$ respectively), indicating that the major weakness of RA is its high porosity.

The compressive and flexural strengths of the mixes were then compared, which are the most important mechanical properties of concrete in concrete mix design. Cubes of 100mm and $100 \mathrm{~mm} \times 500 \mathrm{~mm}$ beams were used for testing the compressive and flexural strength development respectively under the standard curing conditions for 7, 14, 28 and 56 days. Three cubes and beams were tested at 7, 14, 28 and 56 days and then the average strength was taken, according to BS 1881: Part 116 [11] and BS 1881: Part 118 [12] for compressive and flexural strength respectively. Density of hardened concrete was also measured. Furthermore, the static modulus of elasticity using cylinders of $100 \mathrm{~mm}$ diameter under 28-day curing conditions were 
examined based on BS 1881: Part 121 [13]. Three preloading cycles, using the same loading and unloading rate, were used. One hundred and sixty-eight specimens of 500mm x 100mm beams, cubes of $100 \mathrm{~mm}$ and cylinders of $100 \mathrm{~mm}$ diameter had been used for measuring the density, compressive strength, flexural strength and modulus of elasticity respectively.

\section{Experimental Results}

All the mix proportions of recycled aggregate concrete mixed using TSMA and NMA were collected with a slump of $75 \mathrm{~mm}$ as required by $\mathrm{BD}$ [9]. The results of density, compressive strengths, flexural strength and static modulus of elasticity to mixing with different proportions of RA using NMA and TSMA are shown in Figures 1 to 4, Figures 5 to 8, Figures 9 to 12 and Figure 13 respectively. A clear strength enhancement in using TSMA can be found when compared with that of NMA.

<Figures 1-13>

In TSMA, during the first stage of mixing, the use of half of the required water for mixing leads to the formation of a thin layer of cement slurry on the surface of RA which permeates into the porous old cement mortar, filling up the old cracks and voids. In the second stage of mixing, the remaining water is added to complete the cement hydration process. A stronger interfacial zone (ITZ) is thus developed.

The quality of ITZ depends on the surface characteristics of the aggregate particles, the degree of bleeding, chemical bonding and the specimen preparation technique which, however, are difficult to measure. Although these effects have been reported by some investigators, the results are 
difficult to reconcile. Nonetheless, it is generally agreed that as the paste-aggregate bond strength increases, the concrete strength also increases [14]. Figure 14 illustrated the interfacial zone of concrete using TSMA, which is much better than that of NMA shown in Figure 15.

$<$ Figure 14>

$<$ Figure 15 $>$

\section{Optimization on RA Proportions in Using TSMA}

Because the proportions of RA replacement are taken in discrete sampling space, regression of discrete experimental data into a continuous real function is important and necessary for further analysis, like comparison, accumulation, and optimization. The crystallization of concrete is, however, a complex physical-chemical process affected by many ingredients that are hard to control, so the experimental data is usually inevitably noisy. In the some cases, large noises even fake data with high frequency can be found. In comparing the two mixing methods, TSMA and NMA, convictive continuous regression results were assumed so that the representative trends amongst these noisy data could be modeled with robust mathematical methods.

After attempting various mathematical models including polynomial curve fitting, multi-layer perceptron (MLP) and radial basis network (RBN) (all of which bear some problems in analyzing the experimental results [15-17]), General Regression Neural Network (GRNN) was found to work better in harmonizing the noises by introducing a normalized dot product weight function to substitute the weighted sum in RBN [18]. It presents the improvement resulted from different proportions of RA substitutions recorded in the various experimental results. The modeling work is undertaken with Matlab version 7. Improvements of compressive strength, 
flexural strength, and static modulus of elasticity of concrete samples mixed by TSMA and NMA with respect of various percentages of RA substitutions and curing times are shown in Figures 16 to 19, Figure 20 to 23 and Figure 24 respectively. It can be seen that the values obtained by TSMA are higher than those of NMA for any percentage of RA substitution.

$<$ Figures 16 to $24>$

The noise-tolerant regression, it can be used to compare TSMA with NMA quantitatively. The percentage improvements' of TSMA over NMA are shown in Figures 16 to 24. The local maxima with different RA substitutions are also highlighted in each figure. The local maxima and their improvement percentages are tabulated in Table 1.

$<$ Table 1>

From the results of the compressive strength shown in Figures 16 to 19, it is clearly indicated that around 25 to 40 percent of RA substitutions yield optimal properties using TSMA with improvements of 17.39, 10.83, 17.68 and 12.70 percent in 7, 14, 28 and 56 days of curing [the optimal RA percentages obtained were 37.37\%, 36.36\%, 24.24\% and 39.39\% in 7, 14, 28 and 56 days of curing respectively] (see Table 1). Another local maximum happens at around 55 to 70 percent of RA substitution with improvements of 11.93, 6.03, 7.82 and 9.13 percent of 58.59\%, $68.69 \%, 58.59 \%$ and $56.57 \%$ of RA substitution after 7, 14, 28 and 56 days of curing respectively.

Similar situations occurred in flexural strength and static modulus of elasticity. The optimal points occurred at RA substitutions of 39.39\%, 28.28\%, 31.31\% and 29.29\% with improvements 
in flexural strength of $21.79 \%, 21.54 \%, 7.59 \%$ and $12.86 \%$ at 7, 14, 28 and 56 days of curing respectively (see Figures 20 to 23). At 31.31\% of RA substitutions, an improvement of $14.35 \%$ on static modulus of elasticity was recorded (see Figure 24). Furthermore, improvements in flexural strength of 3.56\%, 9.38\%, 2.25\% and 2.40\% with RA substitutions of $60.61 \%, 60.61 \%$, $69.70 \%$ and $67.68 \%$ at $7,14,28$ and 56 days of curing are recorded respectively. An improvement in static modulus of elasticity of $12.07 \%$ with RA substitution of $46.46 \%$ was also recorded.

With the inherent weakness of RA including high porosity, high amounts of cracks, high level of impurity and high cement mortar remains, the mechanical properties of RAC are affected, which is thus limited to lower-grade applications. The pre-mix process can provide a better interfacial behaviour between the aggregate and cement paste. This study has identified that the optimal proportions of RA when using TSMA is around 25 to 40 percent and 50 to 70 percent of RA substitution. Therefore, the current regulation in Hong Kong and other countries limiting the adoption of 20 percent of RA substitution is on the conservative side. The use of TSMA can allow higher percentages of RA substitution.

\section{Conclusion}

Recycled aggregate is strongly advocated by the Hong Kong government such as the motives of setting up the centralized recycling plant, issuance of practice guidelines, specification and technical circulars in guiding the use of recycled aggregate. The porous nature of recycled aggregate reduces the mechanical properties of the recycled aggregate concrete. A series of full scale experiments testing RA substitution between 0 and 100 percent is reported in this paper. 
Optimization of RA substitution is modeled. Around 25 to 40 percent of RA substitution is found to be most favourable in using TSMA. Further, around 50 to 70 percent of RA replacement can also give some improvement although the enhancements are less significant when compared with that of 25 to 40 percent.

\section{Acknowledgments}

The work described in this paper was fully supported by a grant from the Housing Authority Research Fund of the Hong Kong Special Administrative Region, China (Project Ref. No. 9460004).

\section{References}

[1].Kawano H. The state of reuse of demolished concrete in Japan. Integrated design and environmental issues in concrete technology: proceedings of the International Workshop 'Rational Design of Concrete Structures under Severe Conditions': Hakodate, Japan, 7-9 August 1995, London: E \& FN Spon, 1995: p. 243-249.

[2].ERL (Environmental Resources Limited). Demolition waste, Construction Press Limited, Lancaster, England, 1980.

[3]. Mulheron M. The recycling of demolition debris: current practice, products and standards in the United Kingdom. Demolition and reuse of concrete and masonry: reuse of demolition waste, London: Chapman and Hall,1988, p. 510-519.

[4].Hendriks CF. Certification system for aggregates produced from building waste and demolished buildings. Environmental aspects of construction with waste materials: proceeding[s] of the International Conference on Environmental Implications of Construction 
Materials and Technology Developments, Maastricht, the Netherlands, 1-3 June 1994, p. 821-834.

[5]. Collins RJ. Reuse of demolition materials in relation to specifications in the UK. Demolition and reuse of concrete and masonry: guidelines for demolition and reuse of concrete and masonry: proceedings of the Third International RILEM Symposium on Demolition and Reuse of Concrete Masonry, held in Odense, Denmark, 24-27 October 1993, London: E \& FN Spon, 1993, p. 49-56.

[6].Tam WYV, Gao XF, Tam CM. Micro-structural analysis of recycled aggregate concrete produced from two-stage mixing approach. Cement and Concrete Research 2005;35(6):11951203.

[7]. Chan CY, Fong FK. Development in recycling of construction and demolition materials. Civil Engineering Department, Hong Kong, Homepage, available at http://www.ced.gov.hk/eng/services/recycling/development.pdf, 2002.

[8]. Kawano H. Barriers for sustainable use of concrete materials. Concrete technology for a sustainable development in the 21st century, London: New York: E \& FN Spon, 2000, p. 288293.

[9].BD (Buildings Department). Practice note for authorized persons and registered structural engineers: use of recycled aggregates in concrete. Hong Kong, 2003.

[10]. BS 882. Specification for aggregates from natural sources for concrete, British Standards Institution, London, United Kingdom, 1992.

[11]. BS 1881: Part 116. Method for determination of compressive strength of concrete cubes, British Standards Institution, London. United Kingdom, 1983.

[12]. BS 1881: Part 118. Method for determination of flexural strength. British Standards 
Institution, London. United Kingdom, 1983.

[13]. BS 1881: Part 121. Method for determination of static modulus of elasticity in compression. British Standard Institution. United Kingdom, 1983.

[14]. Mindess JF, Young DD. Concrete. Upper Saddle River, NJ: Prentice Hall, 2003.

[15]. Cybenko G. Approximation by superpositions of a sigmoidal function. Mathematics of Control, Signals, and Systems 1989;2:303-314.

[16]. Hartman EJ, Keller JD, Kowalski JM. Layered neura networks with Gaussian hidden units as universal approximations. Neural Computation 1990;2(2):210-215.

[17]. Mitchell TM. Machine Learning. McGraw-Hill Companies, Inc, 1997.

[18]. Specht DF. A General Regression Neural Network. IEEE Transactions on Neural Networks 1991;2(6):568-575. 
Table 1: Local Maxima of Percentages of RA and Respective Improvement Percentages

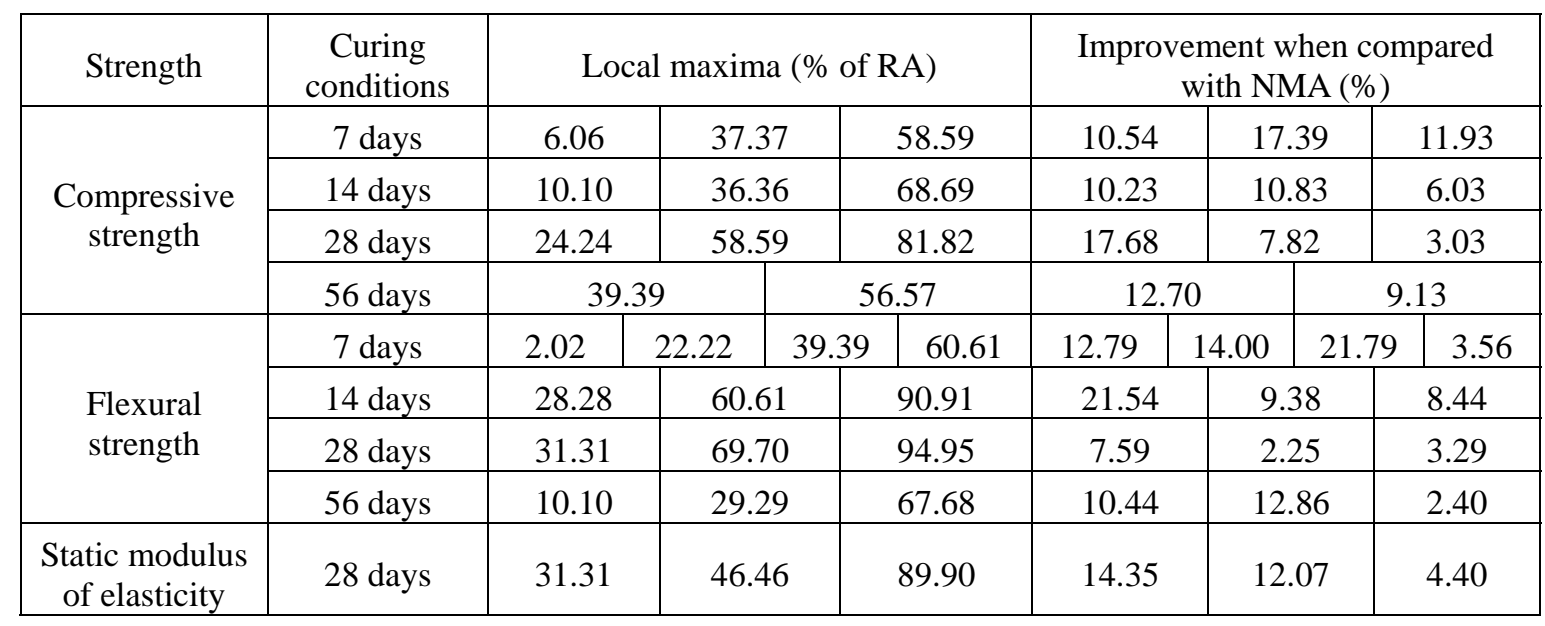




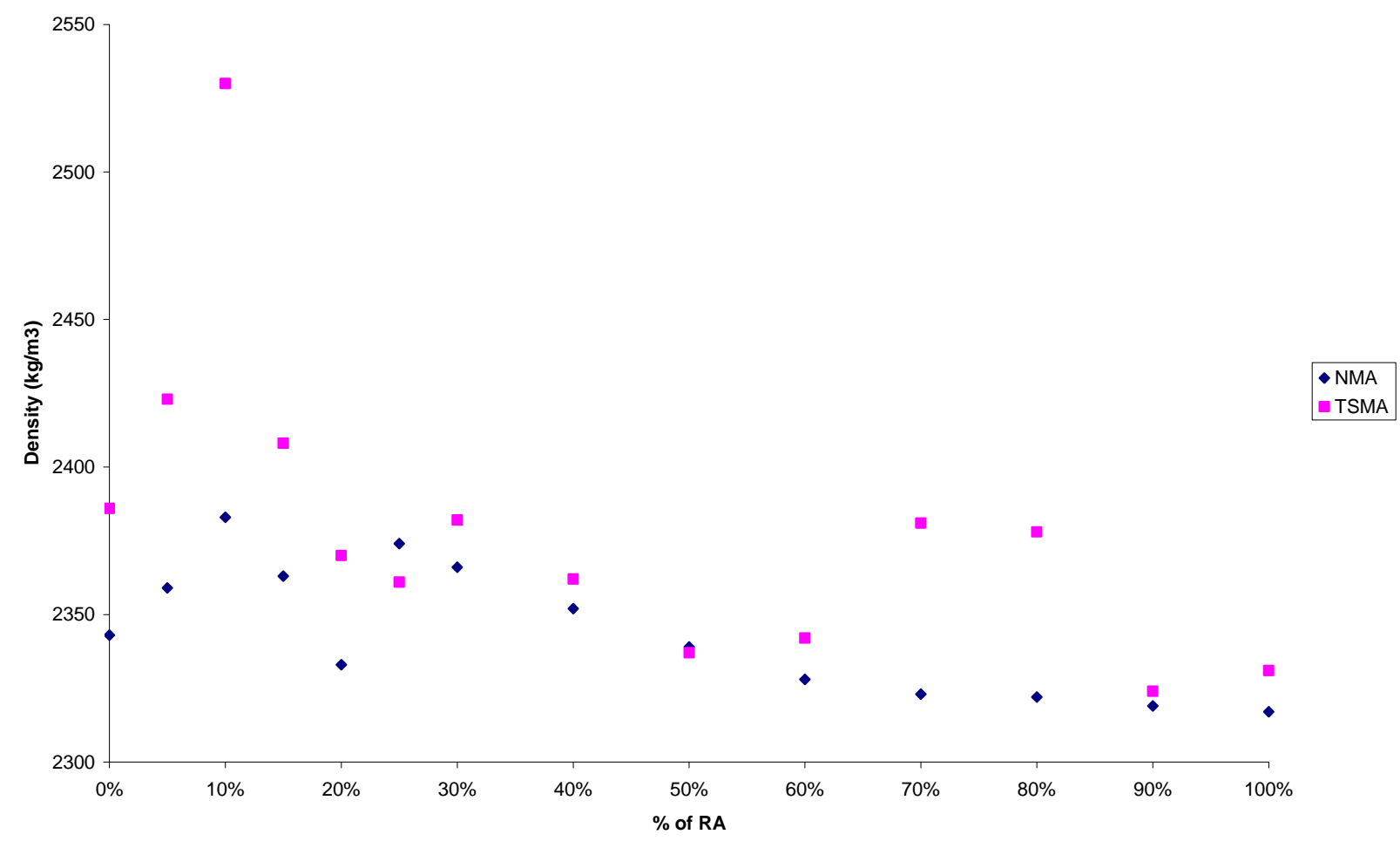

Figure 1: Density of Mixes with Different Proportions of RA Using NMA and TSMA at 7 Days 


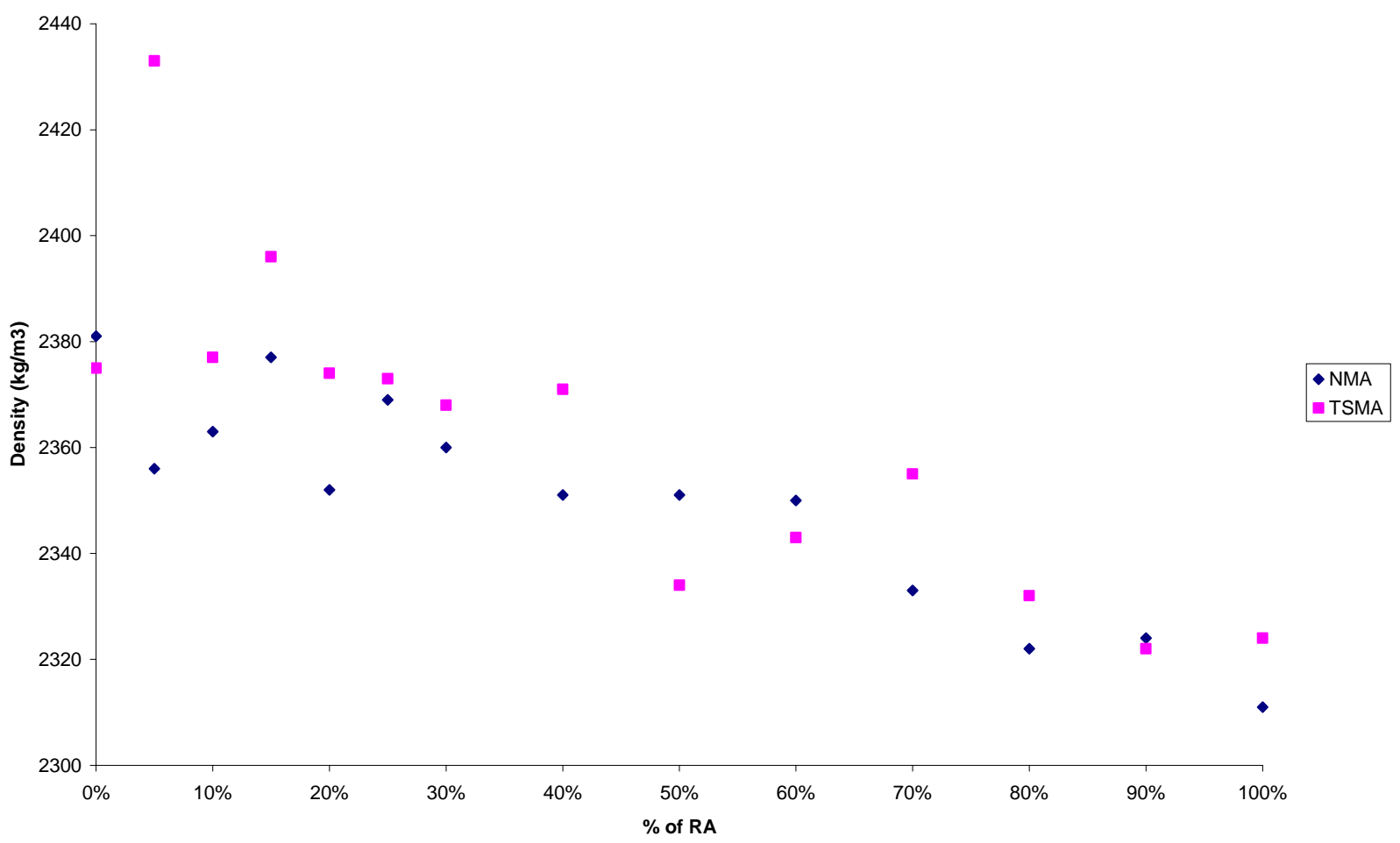

Figure 2: Density of Mixes with Different Proportions of RA Using NMA and TSMA at 14 Days 


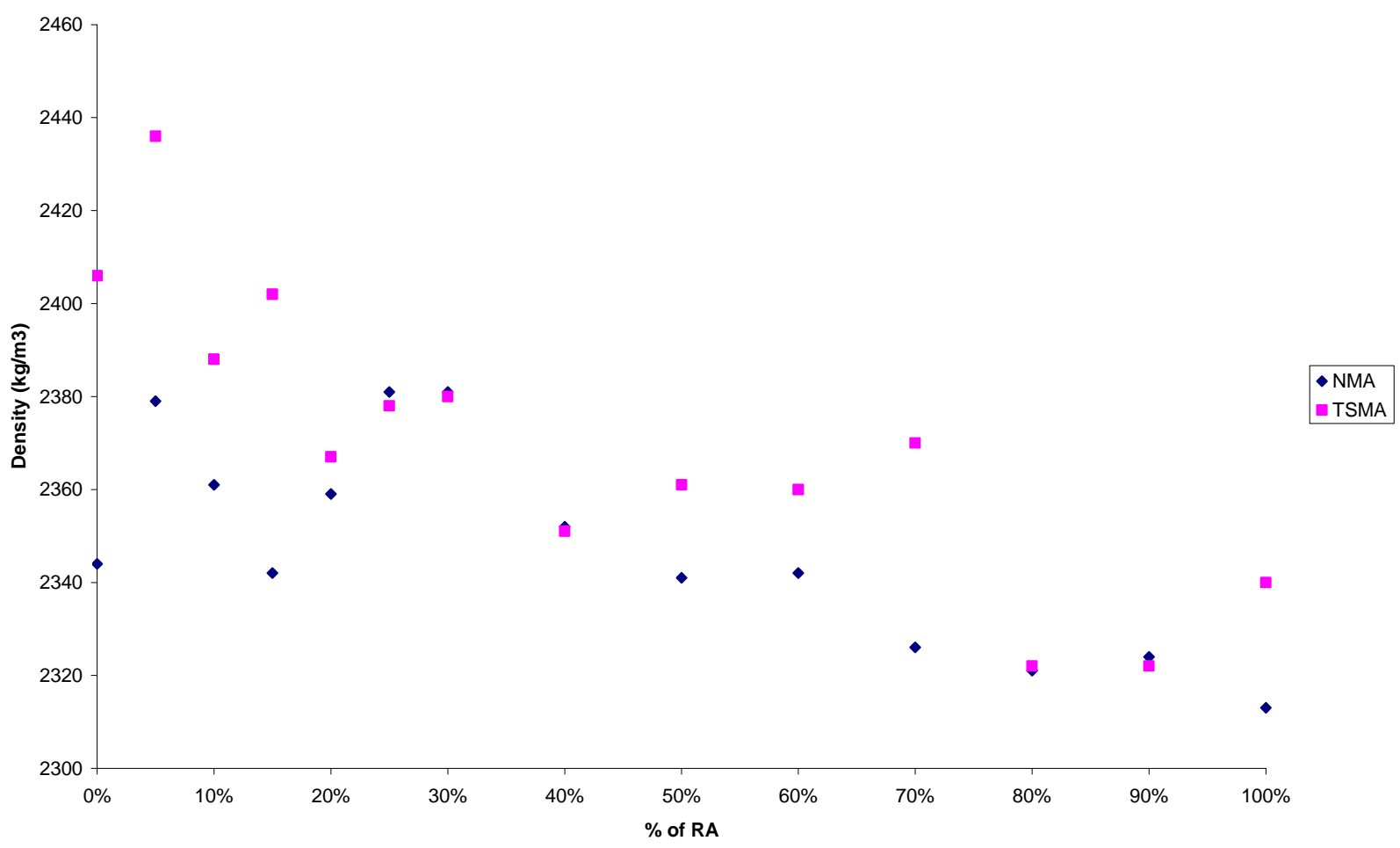

Figure 3: Density of Mixes with Different Proportions of RA Using NMA and TSMA at 28 Days 


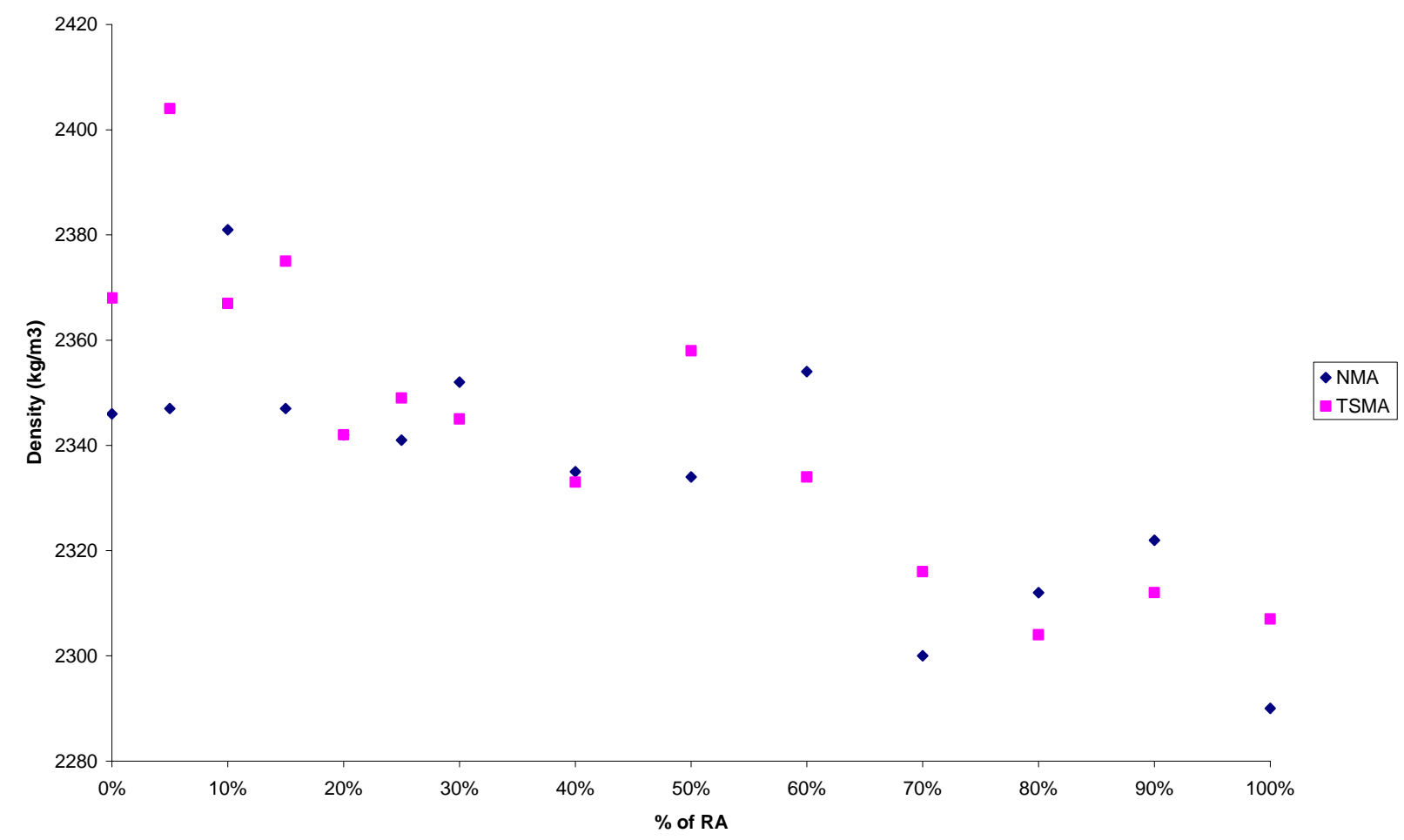

Figure 4: Density of Mixes with Different Proportions of RA Using NMA and TSMA at 56 Days 


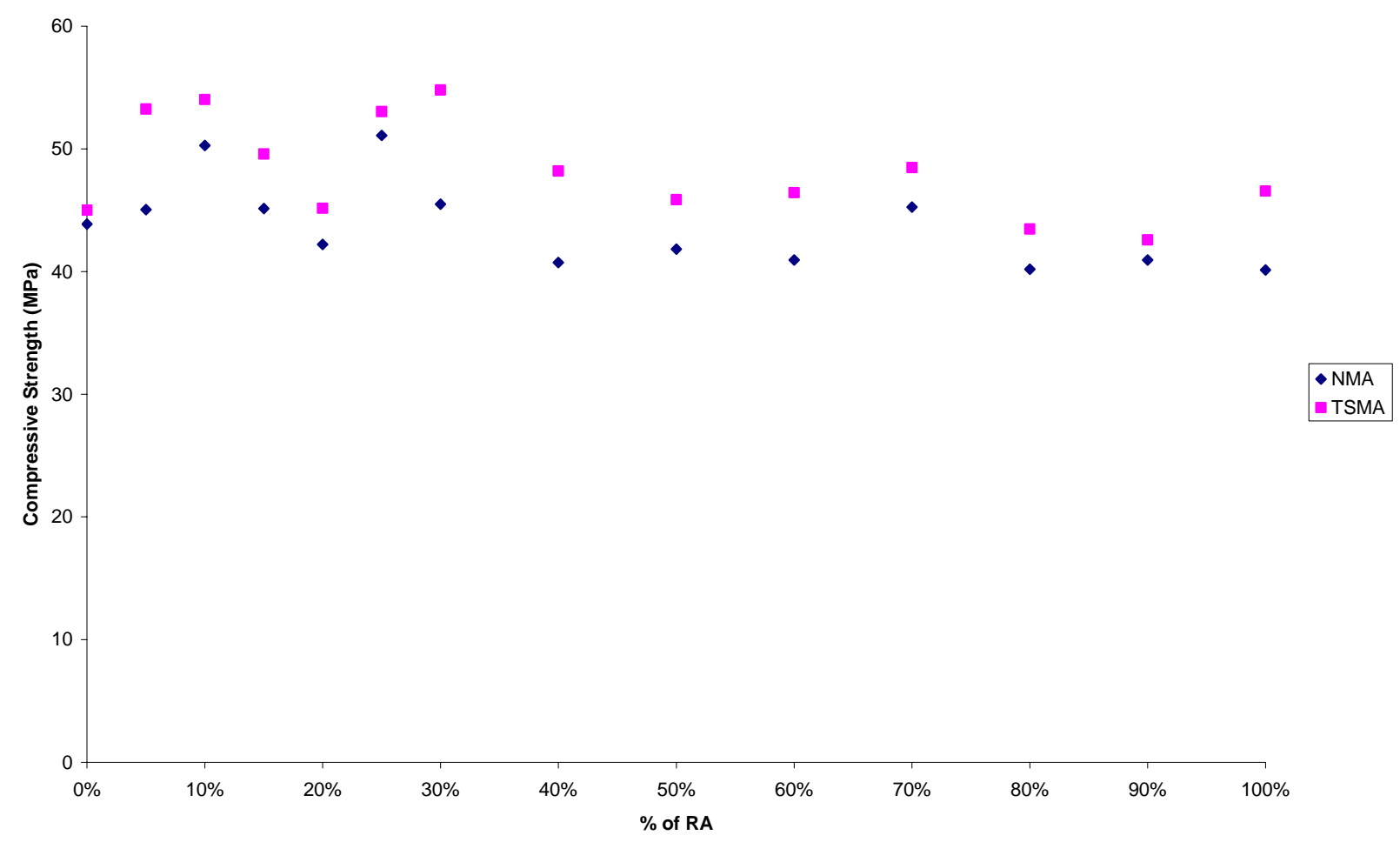

Figure 5: Compressive Strengths of Mixes with Different Proportions of RA Using NMA and TSMA at 7 Days 


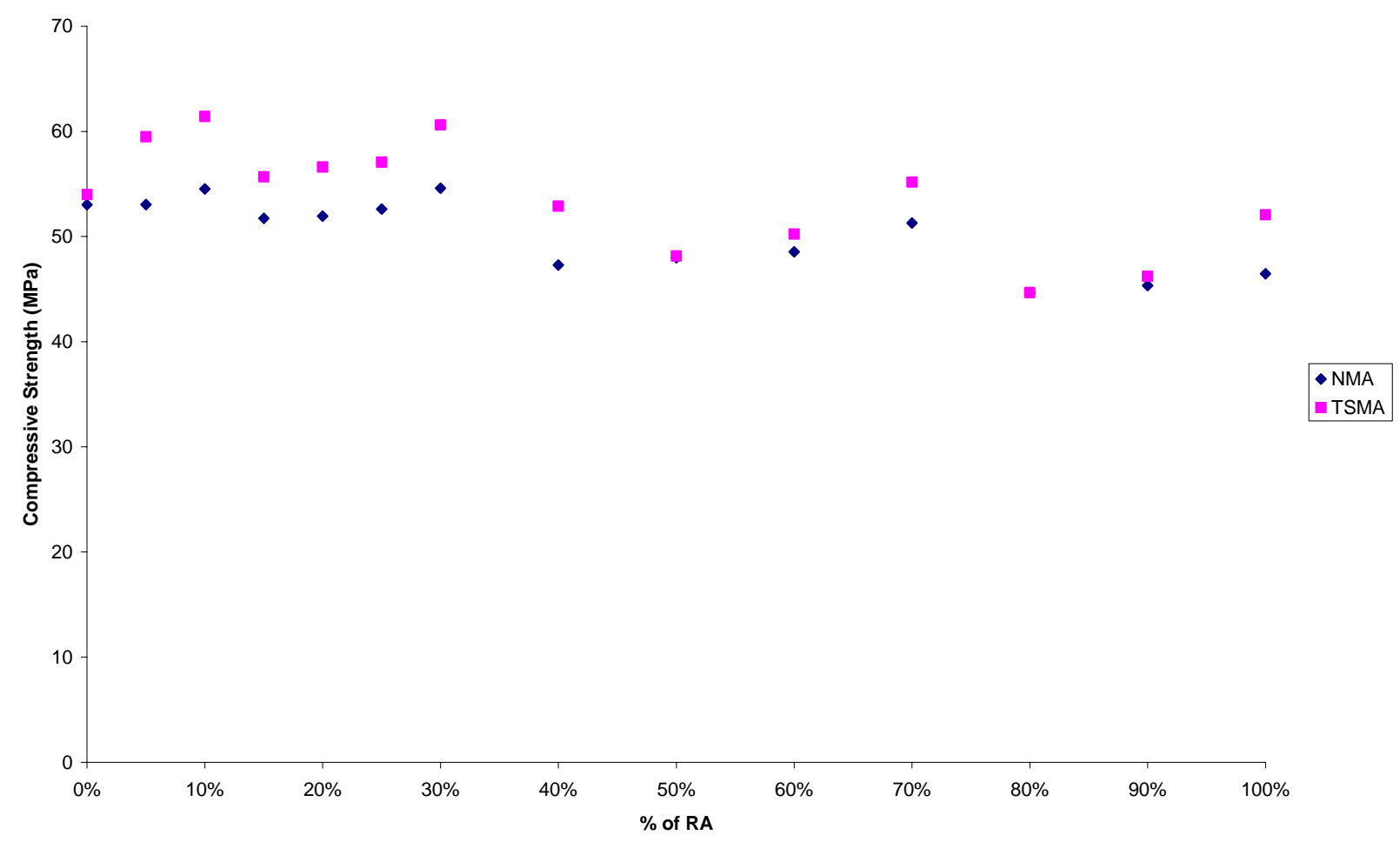

Figure 6: Compressive Strengths of Mixes with Different Proportions of RA Using NMA and TSMA at 14 Days 


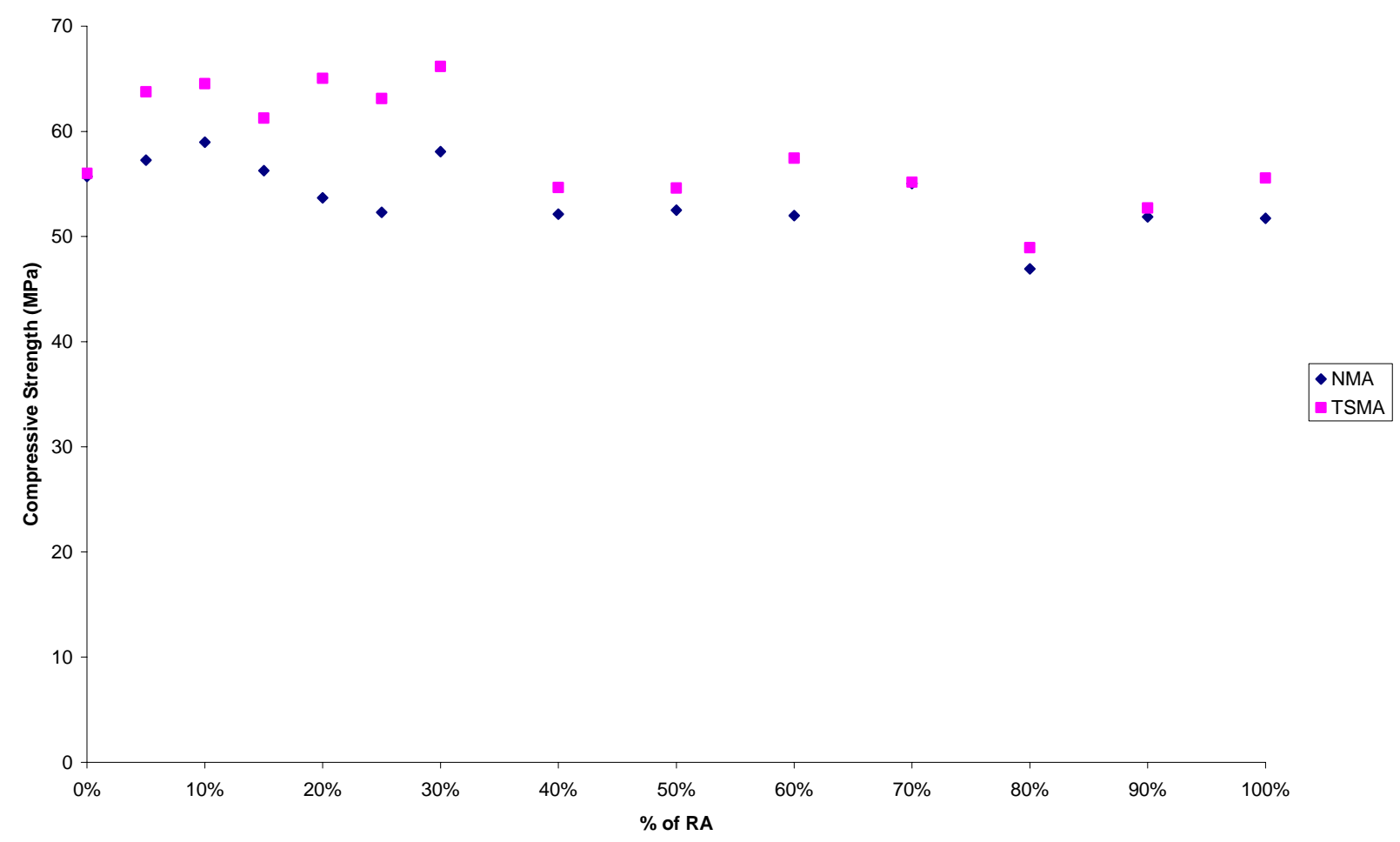

Figure 7: Compressive Strengths of Mixes with Different Proportions of RA Using NMA and TSMA at 28 Days 


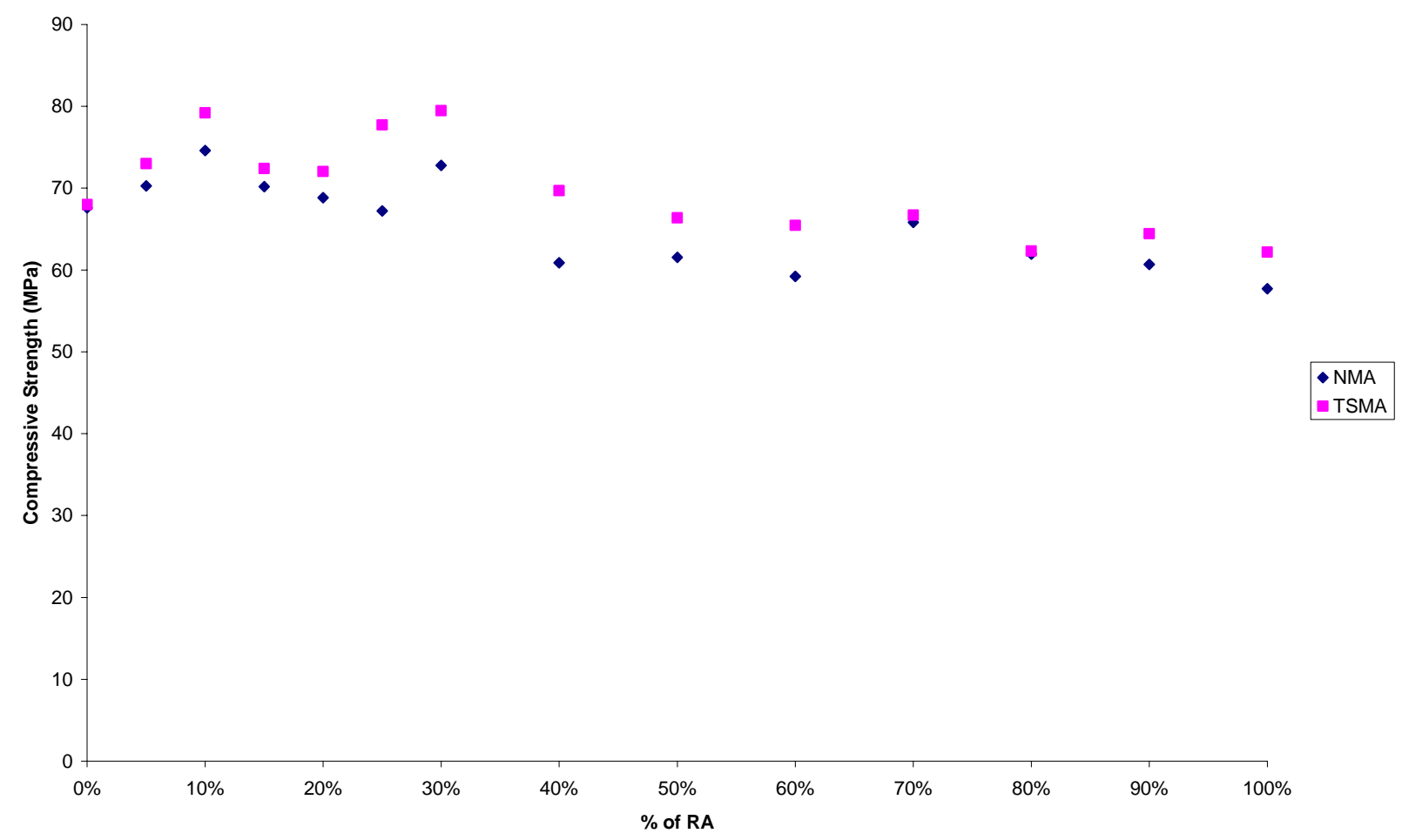

Figure 8: Compressive Strengths of Mixes with Different Proportions of RA Using NMA and TSMA at 56 Days 


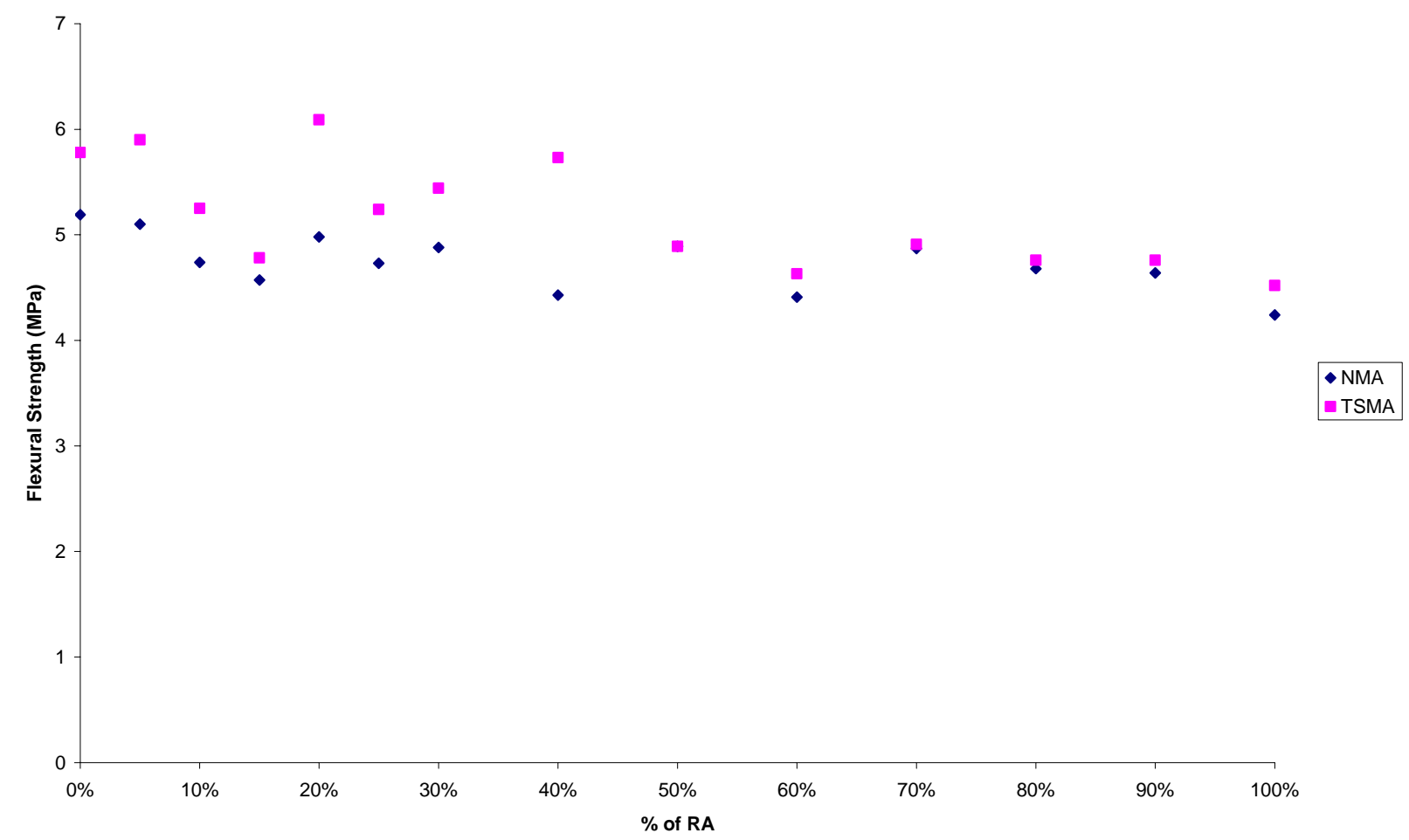

Figure 9: Flexural Strengths of Mixes with Different Proportions of RA Using NMA and TSMA at 7 Days 


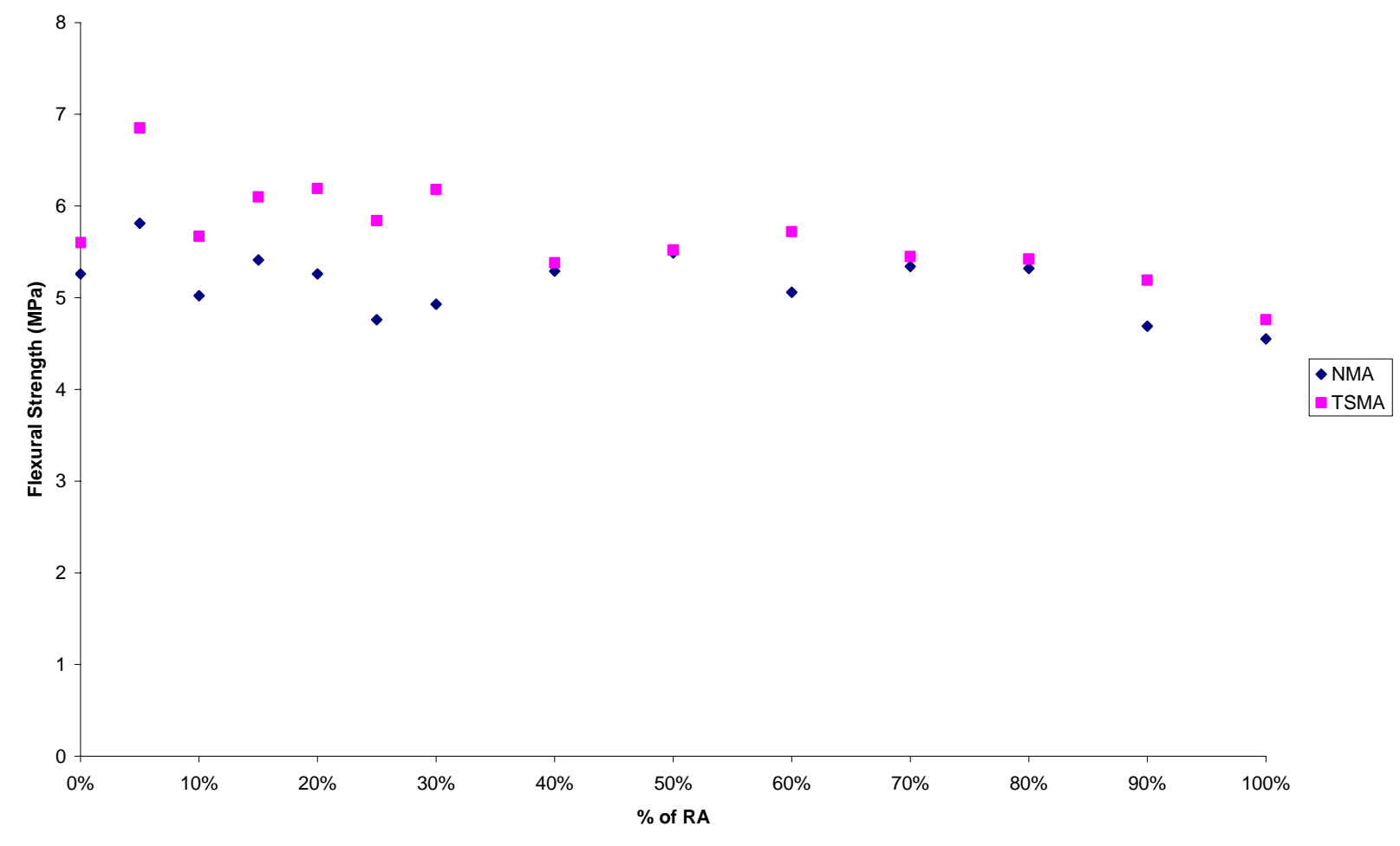

Figure 10: Flexural Strengths of Mixes with Different Proportions of RA Using NMA and TSMA at 14 Days 


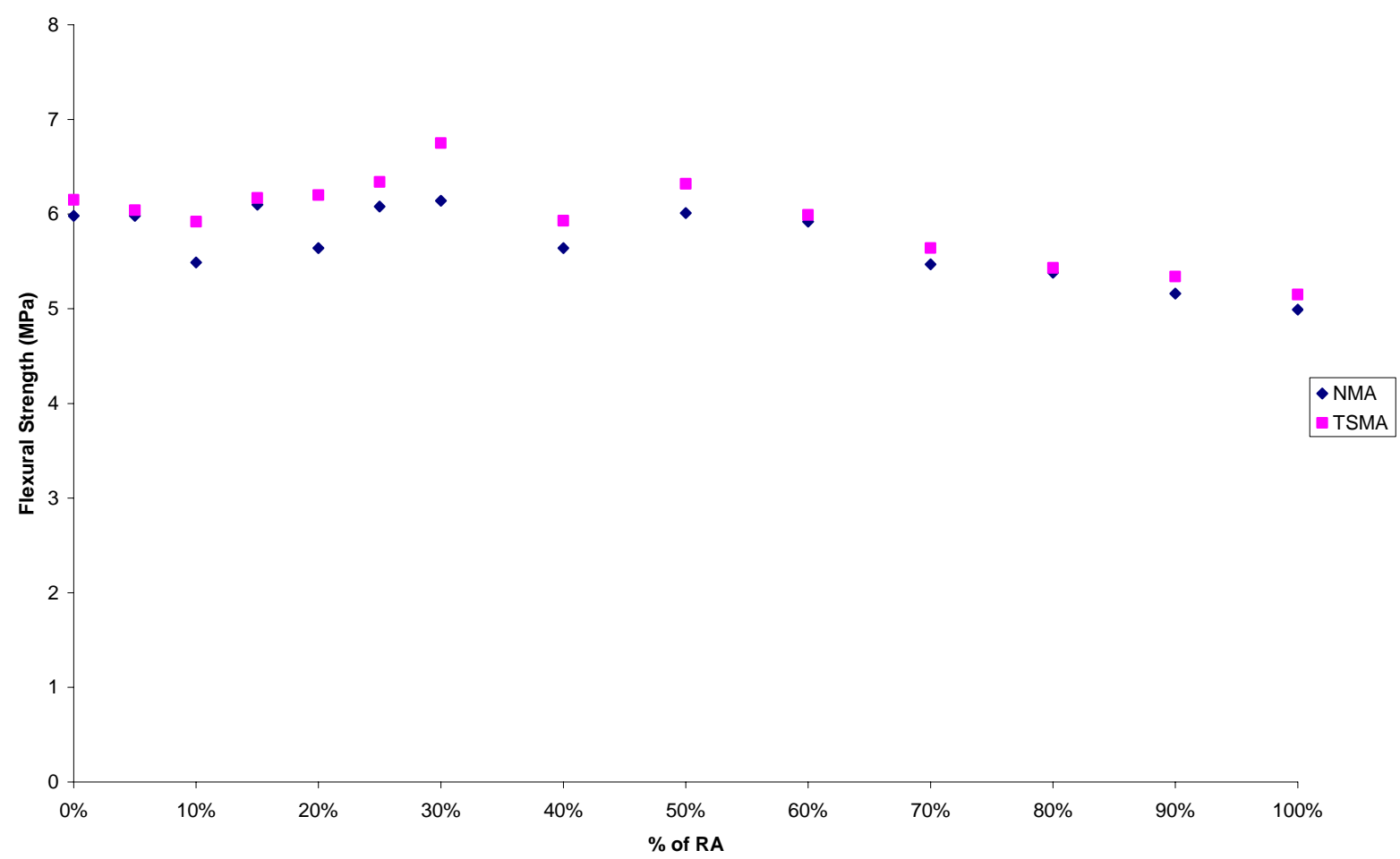

Figure 11: Flexural Strengths of Mixes with Different Proportions of RA Using NMA and TSMA at 28 Days 


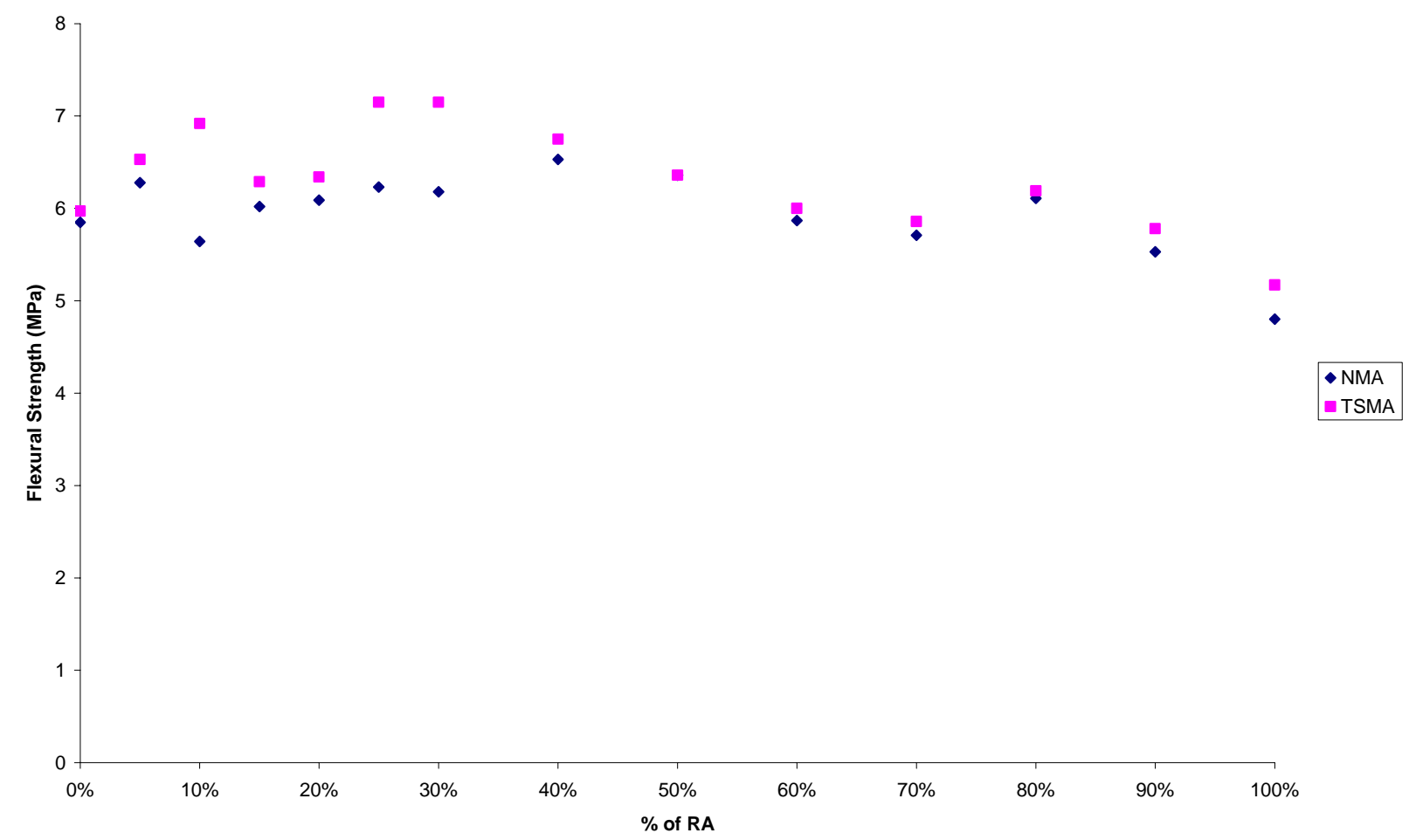

Figure 12: Flexural Strengths of Mixes with Different Proportions of RA Using NMA and TSMA at 56 Days 


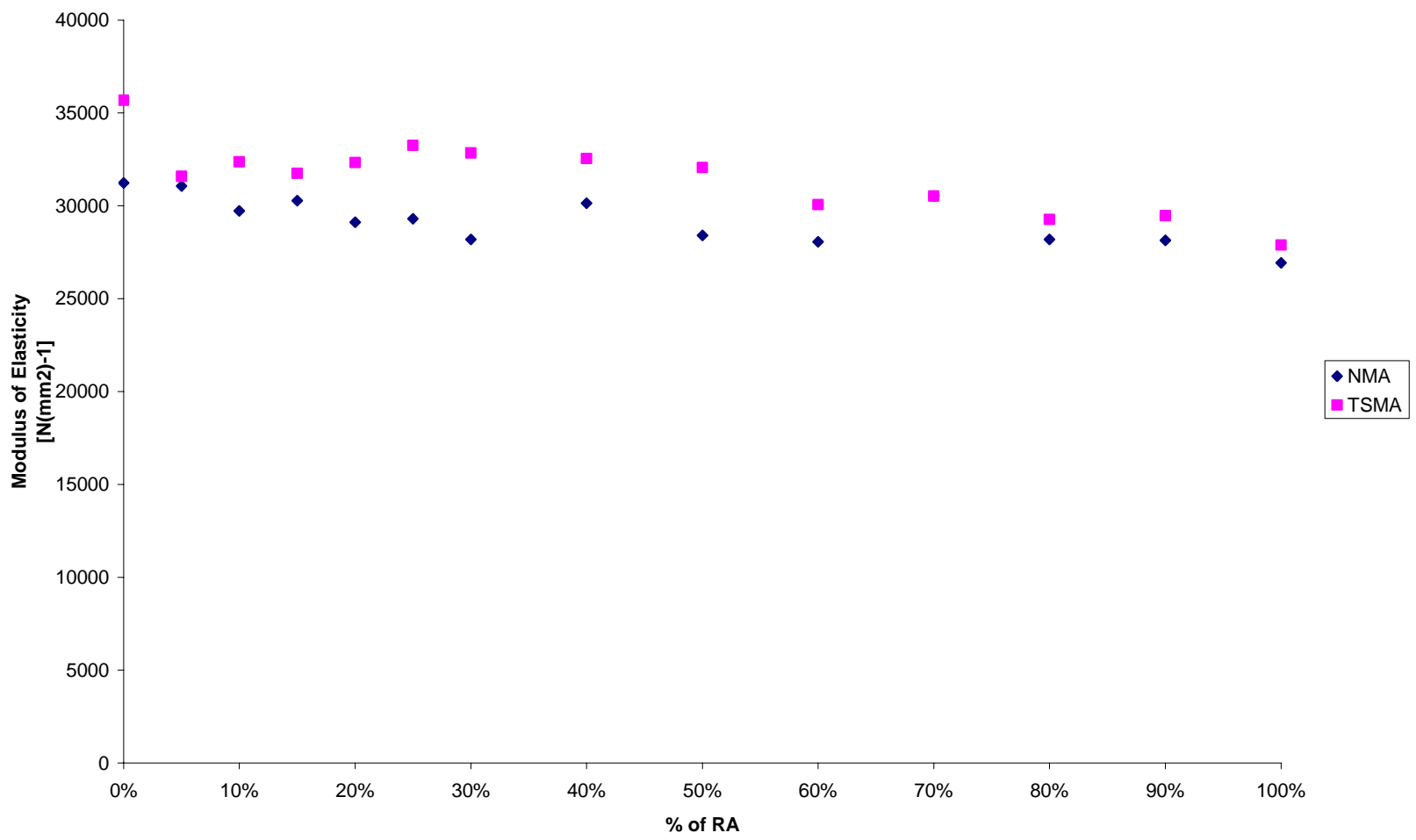

Figure 13: Modulus of Elasticity of Mixes with Different Proportions of RA Using NMA and

TSMA 


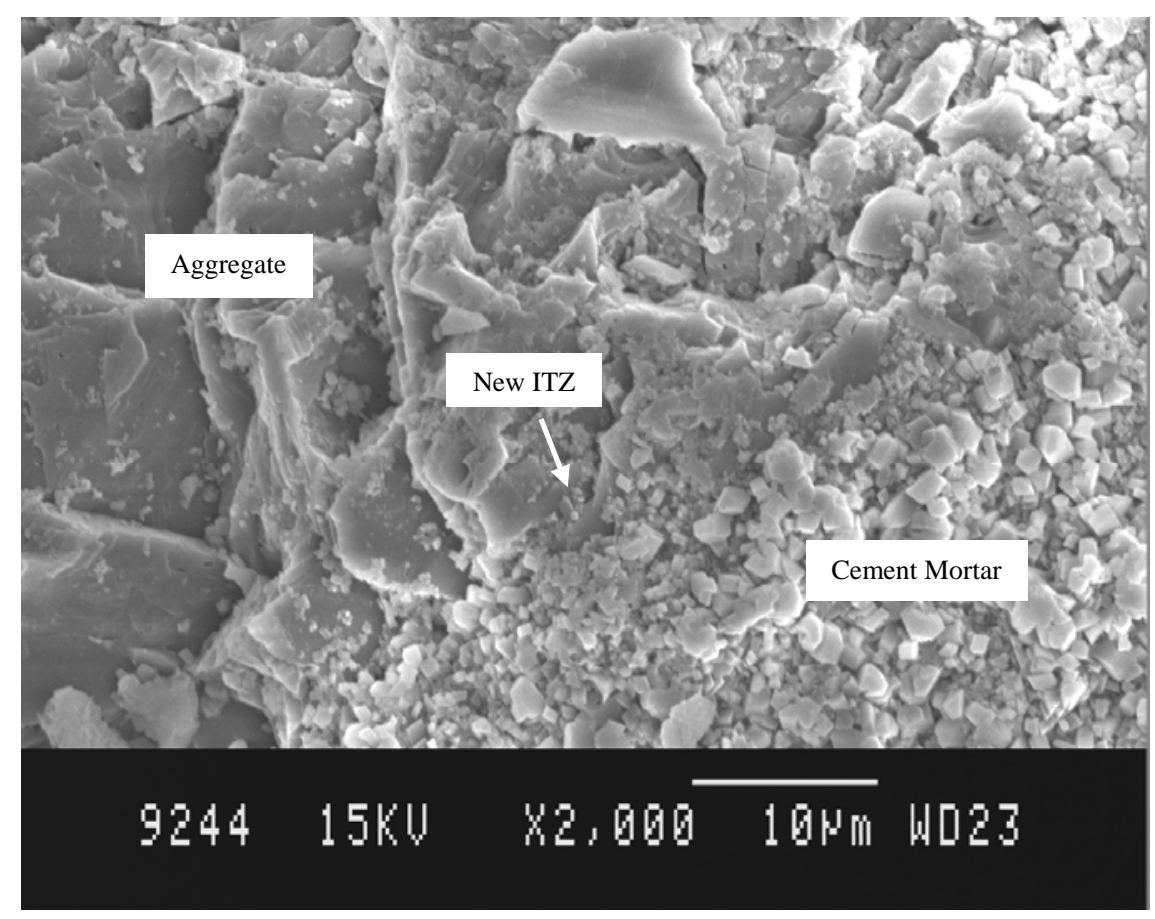

Figure 14: Interfacial Zone for TSMA 


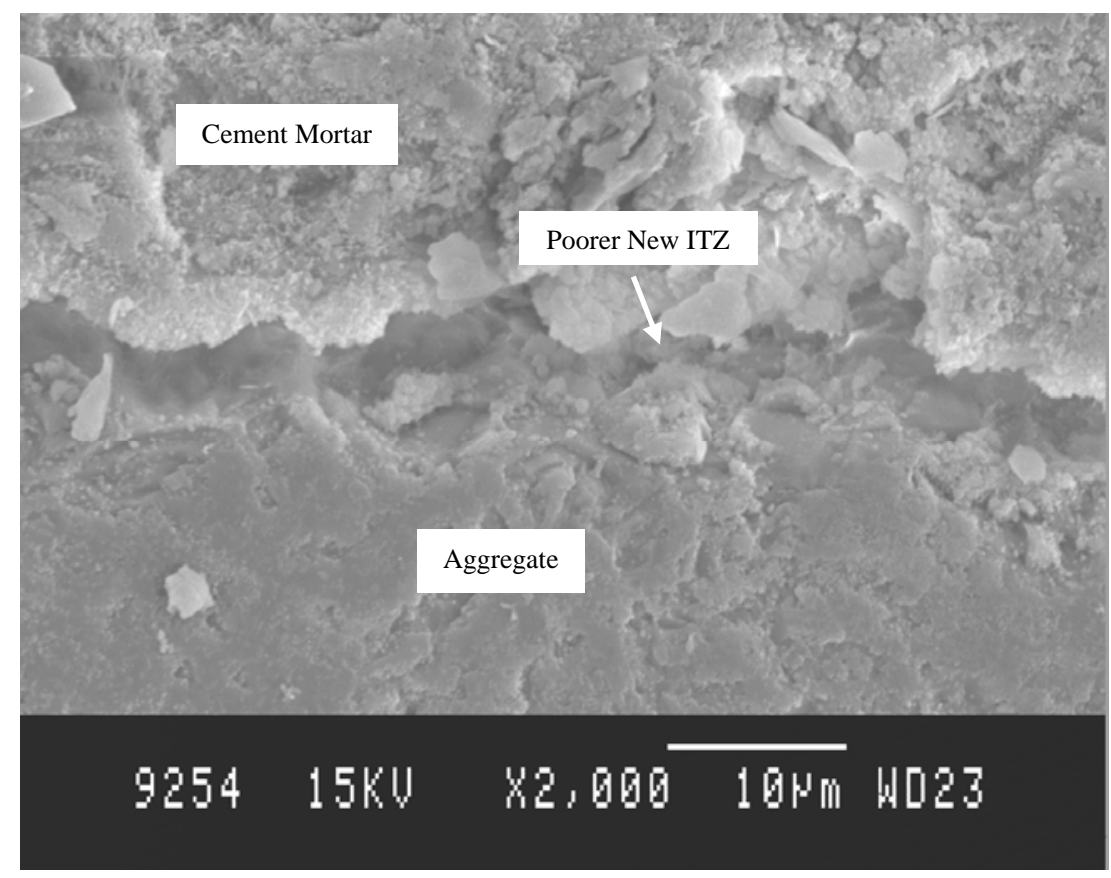

Figure 15: Poorer New Interfacial Zone for NMA 


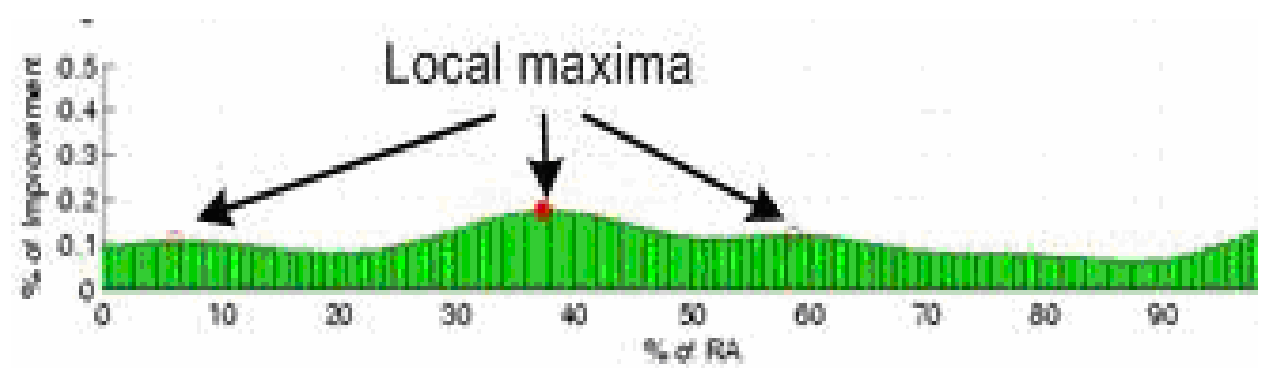

Figure 16: Improvement on Compressive Strength with 7-Day Curing 


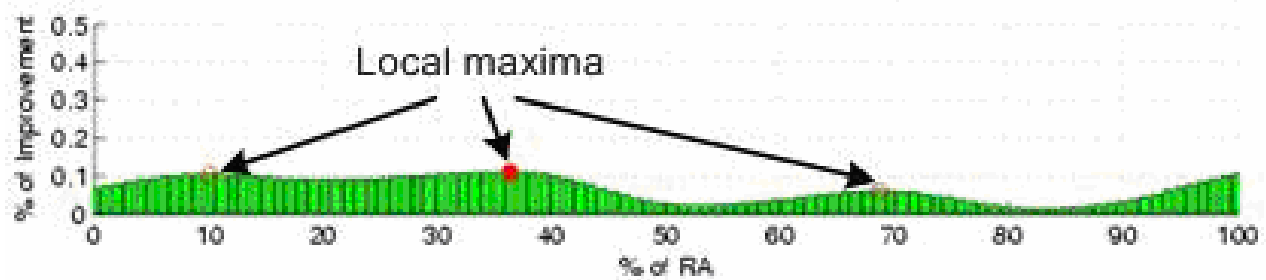

Figure 17: Improvement on Compressive Strength with 14-Day Curing 


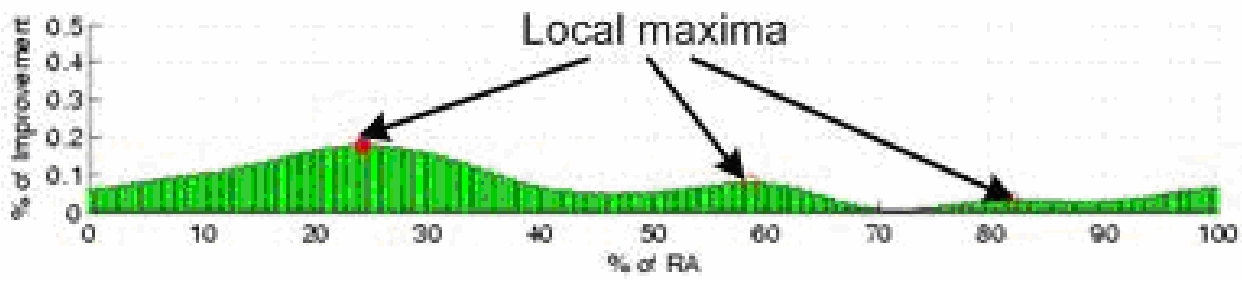

Figure 18: Improvement on Compressive Strength with 28-Day Curing 


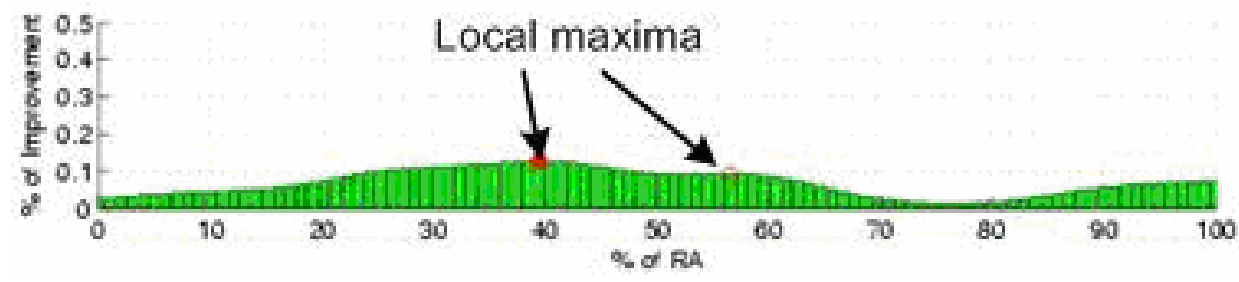

Figure 19: Improvement on Compressive Strength with 56-Day Curing 


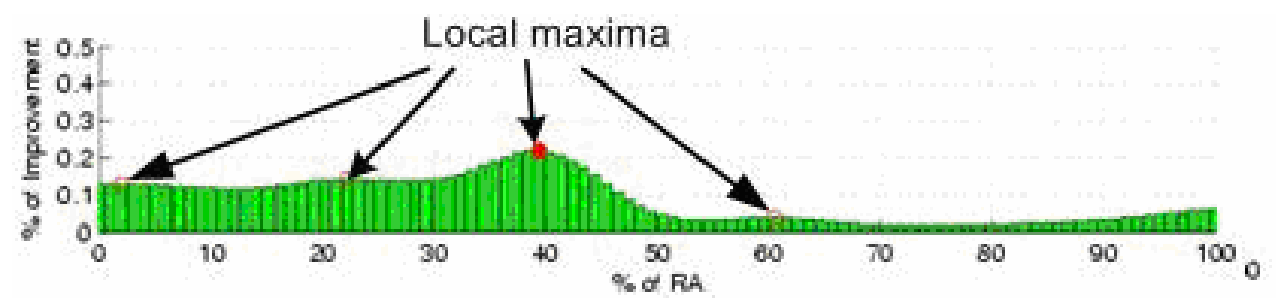

Figure 20: Improvement on Flexural Strength with 7-Day Curing 


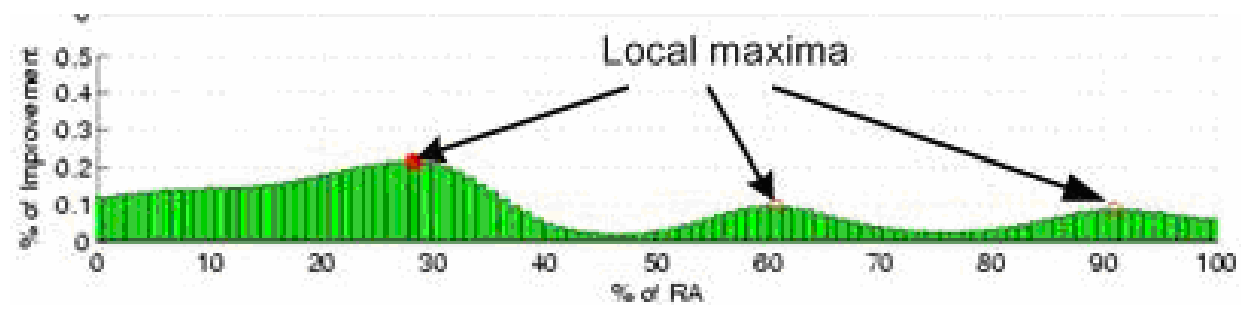

Figure 21: Improvement on Flexural Strength with 14-Day Curing 


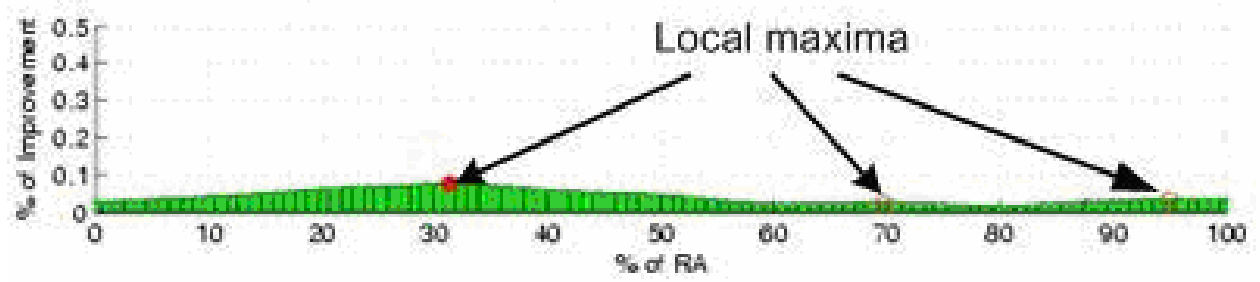

Figure 22: Improvement on Flexural Strength with 28-Day Curing 


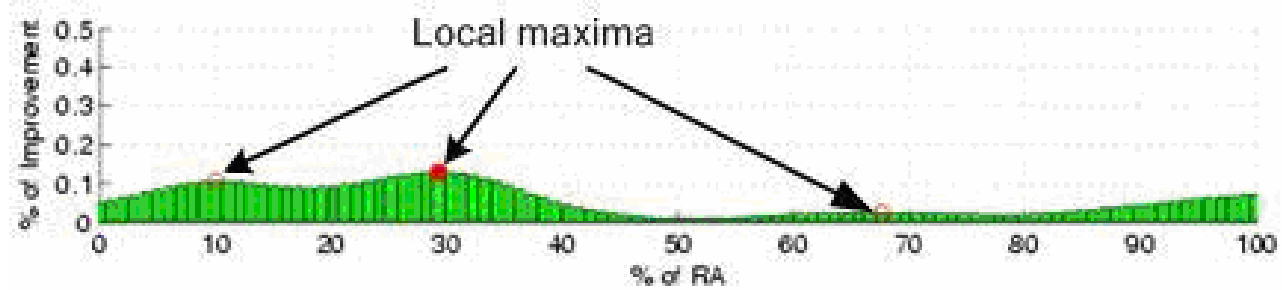

Figure 23: Improvement on Flexural Strength with 56-Day Curing 


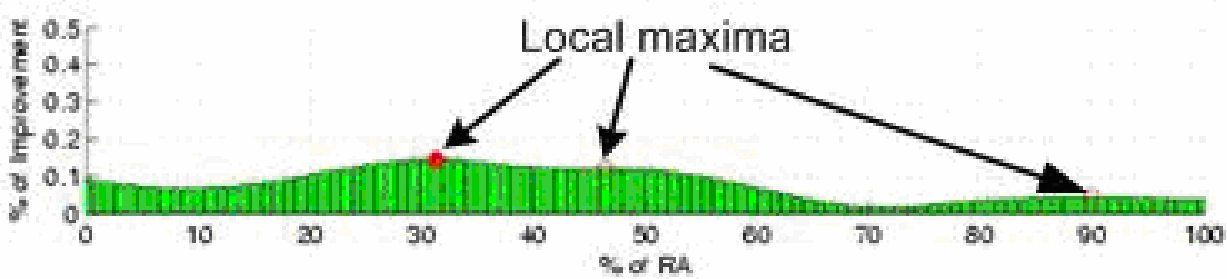

Figure 24: Improvement on Static Modulus of Elasticity with 28-Day Curing 